\title{
Virtual Oscilloscope: Alternative Instructional Materials For Teaching Electronics At The Technical Colleges, In North East Geopolitical Zone, Nigeria
}

\author{
Dr. J. D. Medugu ${ }^{1}$, Prof. J. D. Jiya ${ }^{2}$ \\ ${ }^{I}$ Department of Electrical Technology Education, Modibbo Adama University of Technology, Yola, Nigeria \\ ${ }^{2}$ Electrical Engineering Programme, Abubakar Tafawa Balewa University, Bauchi, Nigeria
}

\begin{abstract}
:
The Study examined the use of virtual oscilloscope as alternative instructional materials for teaching electronics at the technical colleges in North East geopolitical zone of Nigeria. Two research questions were formulated to guide the study. The population for the study consisted of 160 students from four science and technical colleges that offer RTE, from which 124 students were sampled and randomly assigned to either experimental group or control group. A structured questionnaire titled; researcher made achievement test (RMAT) which is same for pretest and the researcher made retention test (RMRT) but numbering varies, were used. It consists of 45 items and a researcher made performance test (RMPT) was used for data collection. The drafts of the RMAT and a table of specification were given to six experts from two universities for validation. The test-retest method was employed for testing the reliability of the instrument. The reliability coefficient obtained was $r=0.78$ and was found suitable. The simple mean and standard deviation were used to analyze the data for answering the research questions. The findings include, the virtual oscilloscope was tested with no problem and could display various waveforms; measure voltages, time and frequency and detect signals. It was recommended among others that; due to its numerous advantages, which include large screen using data projector for demonstration, easier to operate, portability, among others. All hands must be on deck, to see that the virtual oscilloscope is purchased by all concerned and used to complement the real oscilloscope for teaching not only RTE but all related areas.
\end{abstract}

Keywords: Achievement test, Instructional materials, Performance test, Real oscilloscope, Virtual oscilloscope

\section{Introduction}

If a learner's creative life is to be fostered, then the efficacy of the teacher has to be central, since it is the teacher in the classroom that can facilitate the development of the learner's practical knowledge. It is in apparent realization of this that, section 7 (b) of Decree No. 16 [1] has stated, among others, that the purpose of teacher education, "should be to encourage the spirit of enquiry and creativity in teachers" it is important to reiterate that the issue of practical work must not be left as a mere statements of intentions in government official

documents.

According to the National Business and Technical Examination Board (NABTEB) syllabus [2] Radio, Television and Electronics Work (RTE) is among the trades offered at the technical college level. These trades are known as engineering trades, and they are practically oriented ([2]'. In spite of governments' efforts in providing instructional materials, the achievement of some of the objectives for providing functional vocational and technical education has been elusive. The implication is that most students who graduated from these colleges are not properly trained, which is equally responsible for seventy percent $(70 \%)$ failure rate of the WAEC technical examination [3]. Similarly, the NABTEB 2007and 2008 chief Examiners Report stated that, the candidate's weaknesses among others include:

i. The candidate's response to practical questions was very poor

ii. Majority of the candidates had very poor knowledge of sketches and schematic diagrams.

The same document suggested the following:

a. Instructional materials should be provided by the schools to help both teachers and the candidates in the teaching and learning processes.

b. The subject teachers should teach trouble-shooting skill properly to the candidates. Similarly, the National Council on Education (NCE) has viewed with great concern, what they called unsatisfactory state of academic facilities in institutions [4]. But, we know that one of the tragic consequences of inadequate supply and use of instructional materials is low educational standard. Hence, the need to seek alternative instructional materials in the face of dearth cannot be over-emphasized. Therefore in such situation, the production and use of virtual materials cannot be over-emphasized in a developing country like Nigeria where manufactured ready - made instructional materials are not readily available or are too expensive to 
acquire for practical purposes.

Virtual in this case, refers to a computer behaving like oscilloscopes but not in the real case. This is possible with the aid of a developed software packages. According to [5], computer software is a set of programme that tells the computer what to do and how to do it. It is a coded instruction that the computer uses to accomplish a specific tasks for the user.

This Software can be downloaded from the internet free of charge or can be bought for just a little money. According to [6] and [7], computer prices have fallen drastically. They cited an example that a fairly used Pentium IV (Personal Computer) that can now be purchased at about N19, 500:00. Hence, the use of a computer as a virtual oscilloscope (VO) to teach students would be cheaper than buying an oscilloscope which is expensive and not easy to come by. Since the government and heads of institutions are more willing to buy computer systems than Oscilloscopes to enhance computer literacy, it is fitting to extend the capabilities of the Personal Computer (P C) to that of an oscilloscope.

Literature shows number of studies on instructional materials in technical education [8]; [9], and [10]. However, most of the research concentrated on problems and prospects of improvisation with little or no, on virtual instructional materials at the technical colleges. The focus of this study is to use an oscilloscope card and software that can convert a computer to an oscilloscope, to determine: various waveforms, measure voltage, detect signals injected into circuit and for trouble shooting.

\subsection{Purpose of the Study}

i. To determine if virtual oscilloscope can display various waveforms, measure voltages, detect signals injected into circuits and be used for trouble shooting.

ii.

To determine the results of the pretest, posttest and delayed posttest mean scores

for virtual and real oscilloscope in performance and achievement test

\subsection{Research Questions}

1. To what extent can the Virtual Oscilloscope be used to determine various waveforms, measure voltages, detect signals injected into circuit and be used for troubleshooting?

2. What are the pretest, posttest, and delayed posttest mean scores and standard deviations for group I Virtual Oscilloscope, and for group II Real oscilloscope from the four technical colleges?

\section{Methods and Materials}

The study was undertaken in the North East Geopolitical zone. The zone is located in the Northern part of Nigeria. A total of 124 part II RTE students were randomly drawn from four technical colleges. The colleges were the only college that offers RTE trade in the North East Geopolitical zone. The design of this study is pretest posttest control group experimental design. In each college, an intact class was individually randomly assigned to either experimental group (Ge) or control (Gc).

A 45 item research instrument tagged researcher pretest (RMP), Researcher made achievement test (RMAT), researcher made performance test (RMPT) and researcher made retention test (RMRT) were used. The contents of RMP, RMAT and RMRT were same but numbering varies to avoid remembrance. They were multiple choice items with four options A - D, each correct response attracted 2.22 marks; while RMPT, uses rating scales. The draft of the instruments were submitted to six experts of varied years of teaching RTE from Modibbo Adama University of Technology, Yola and University of Nigeria Nsukka, for their comments and suggestions.

It was later pilot tested at government science technical college Takum, Taraba state, where 38 students from RTE class were involved in the exercise. The pilot test results produced a reliability coefficients of $r=$ 0.78

The instruments consist also of Real oscilloscope (RO), a teaching aid supposed to be used for teaching and learning purposes at technical colleges but very expensive and very difficult to find in colleges. Virtual oscilloscope (VO); a teaching aid used to teach experimental group. This teaching aid requires the use of computer for it, to work.

The questionnaire was directly administered to the students after teaching. The chosen level of significance for the study was 0.05 . The simple mean and standard deviation were used to analyse the data for answering the research questions.

\section{Result}

\subsection{Research Question One: To what extent can the VO be used to determine various waveforms, \\ measure voltages, detect signals injected into circuit and be used for troubleshooting?}




\subsubsection{Determine various waveforms}

The Pico scope (Virtual Oscilloscope) was successfully tested with no problem. When the signal generator built by the researcher was connected and signals fed to the computer where the Pico scope was interfaced, various waveforms were observed on the screen of the computer as they were monitored by the researcher. These are shown in figures figures I, II, III and IV as samples.

\subsubsection{Voltage measurement}

Since this is a digital virtual oscilloscope; it had reduced the errors due to analog conversions and observations, calculations, time saving among others. In this case, reading becomes very simple, because already the display is in volts. For instance figure $\mathrm{I}$, gives $6 \mathrm{~V}$ peak to peak at a glance.

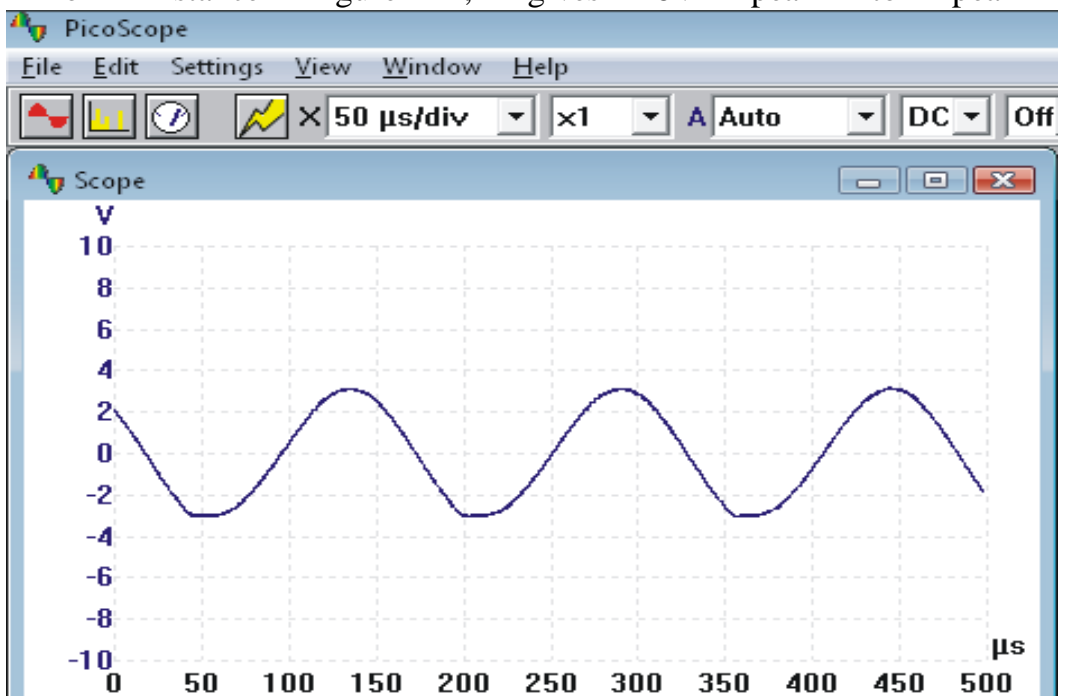

Figure. I: Sinusoidal wave from the virtual oscilloscope showing easy voltage measurement

i. $\quad$ Since, $F=\frac{1}{T}$, frequency and time can also be calculated as follows: Thus, in fig. II:

Voltage $=8 \mathrm{v}$

Multiplier $=\mathrm{x} 1$

Setting, time base $=5 \mathrm{~ms} / \mathrm{div}$.

$$
5 \times 4=20 \mathrm{~ms}
$$

Hence, $\mathrm{t}=20 \mathrm{~ms}\left(20 \times 10^{-3}\right.$ seconds $)$

Therefore, Frequency, $F=\frac{1}{T}$

$$
\begin{aligned}
F & =\frac{1}{20} \times \frac{1000}{1} \mathrm{HZ} \\
& =50 \mathrm{HZ}
\end{aligned}
$$

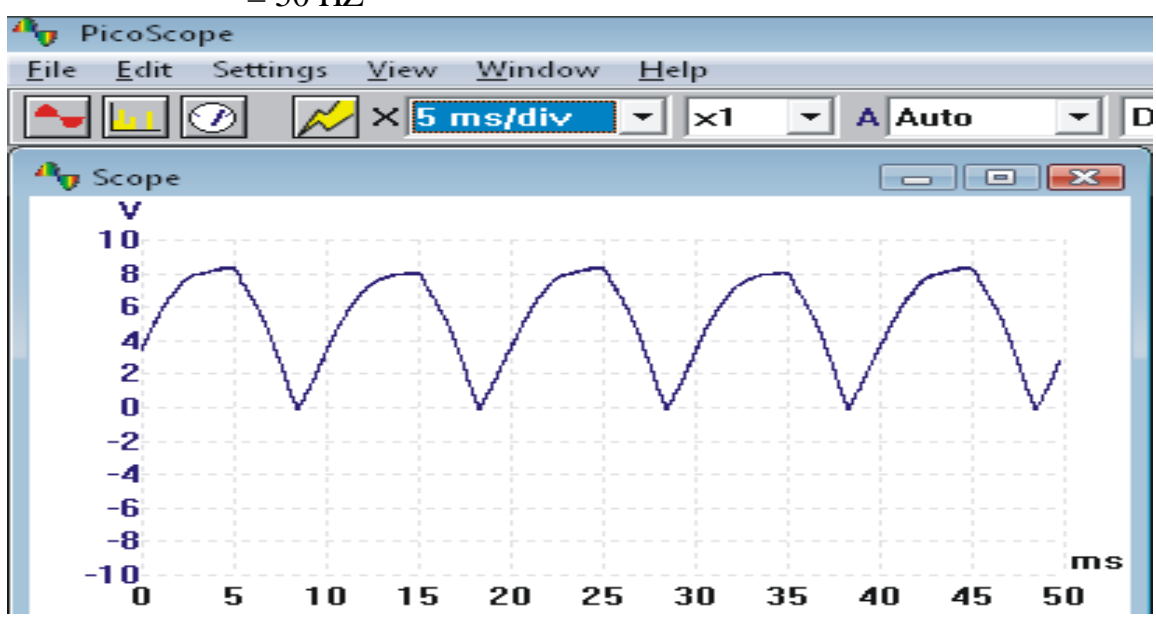

Figure. II: DC full wave unfiltered rectifier, used for calculating time and frequency 


\subsection{Detecting signal / troubleshooting}

In fig. III, the researcher fed into the amplifier a low signal of $150 \mathrm{mv}$ from the locally built signal generator, the amplifier output was observed to be $3 \mathrm{~V}$ on fig. IV.

This result shows:

i) signal has been detected from a signal generator

ii) the signal was a replica of the input signal,

iii) the amplifier was good, since the output was higher than the input signal

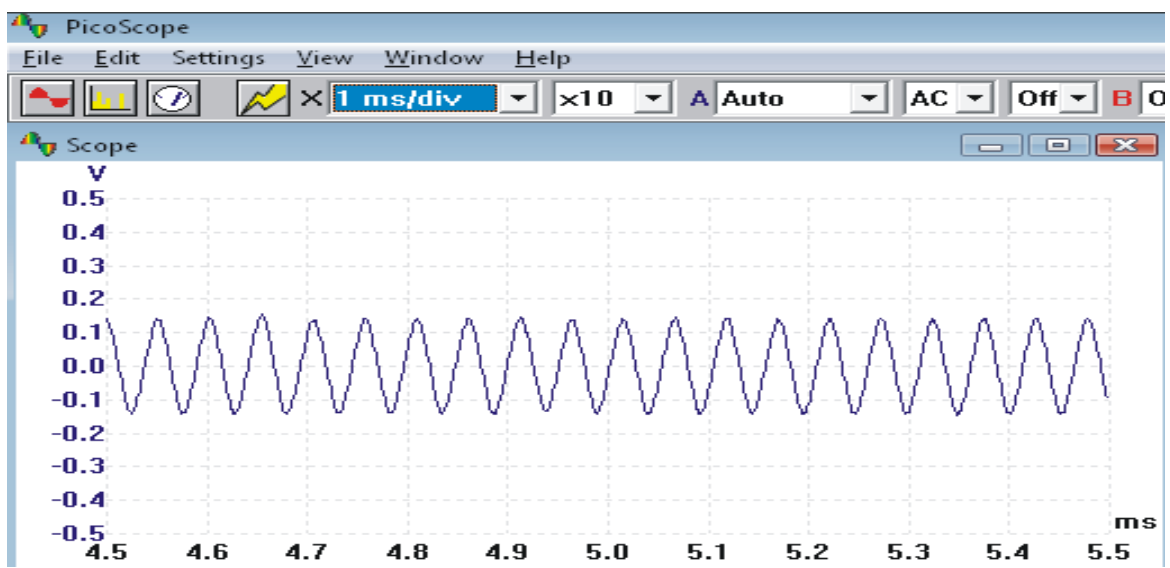

Figure.III: Amplifier input, 150

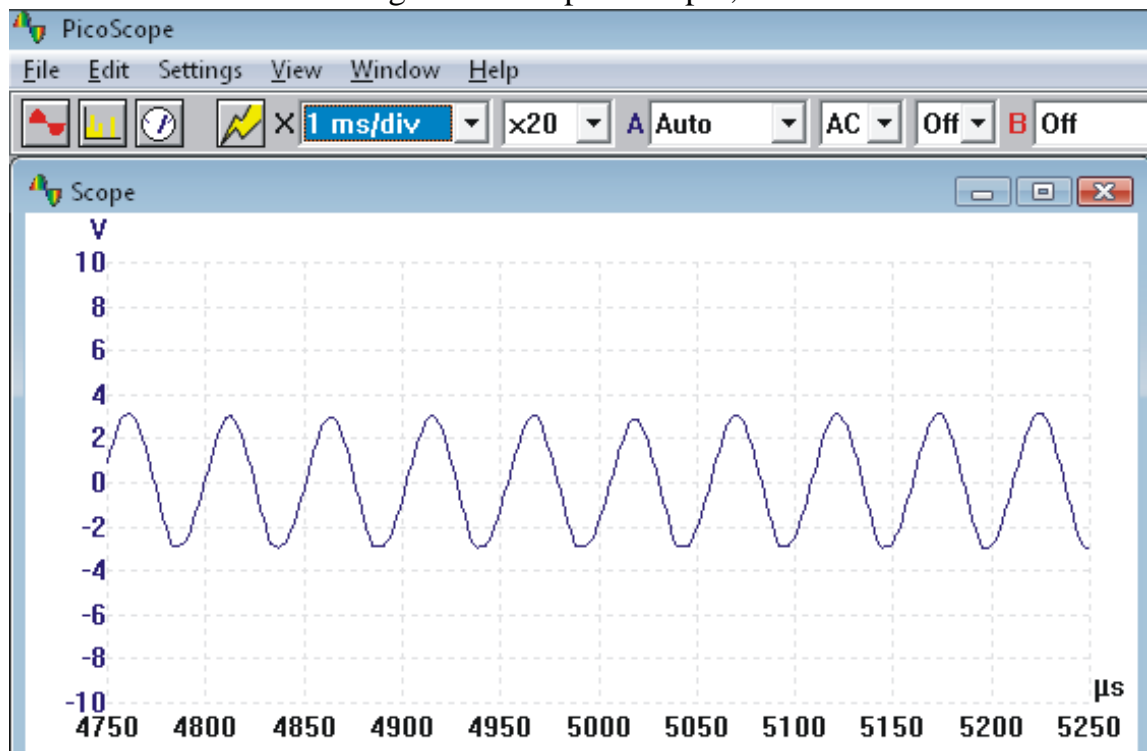

Figure. IV: Amplifier output, 3V

3.2 Research Question 2: What are the pretest, posttest, and delayed posttest mean scores and standard deviations for group 1 Virtual Oscilloscope, and for group 11Real oscilloscope from the four technical colleges?

TABLE 1 show, the means for group $I$, is: pretest $(X=43.58)$, posttest RMAT $(X=66.29)$, posttest RMPT ( $X=67.32)$ and delayed posttest ( $X$ 64.66). The means for group II are: pretest $(X=44.39)$, posttest RMAT $(X=56.18)$, posttest RMPT $(X=53.16)$, and delayed posttest $(X=47.15)$.

As shown in Table 1, posttest and delayed posttest means in group 1, are $X=66.29$ and $X=64.66$ respectively. The posttest and delayed posttest means for group II, are $X=56.18$ and $X=47.15$, respectively. In both groups, learning occurred, but students in group 1(virtual oscilloscope) performed better than students in group II (real oscilloscope). Similarly, the result further show that those in group 1 could retain what they learned over a period of time better than those in group II. 
TABLE 1: Group mean scores, Standard deviations, minimum and maximum Scores

\begin{tabular}{|c|c|c|c|c|c|}
\hline Variable & $\mathbf{N}$ & Mean & Std. D. & Min. & Max \\
\hline \multicolumn{6}{|c|}{ Group I: Virtual Oscilloscope } \\
\hline Pretest & 62 & 43.58 & 3.44 & 40.00 & 53.00 \\
\hline Posttest RMAT & 62 & 66.29 & 7.89 & 49.00 & 82.00 \\
\hline RMPT & 62 & 67.32 & 8.43 & 44.00 & 81.00 \\
\hline Delayed posttest & 62 & 64.66 & 7.02 & 48.00 & 81.00 \\
\hline \multicolumn{6}{|c|}{ Group II: Real Oscilloscope } \\
\hline Pretest & 62 & 44.39 & 4.04 & 40.00 & 57.00 \\
\hline Posttest RMAT & 62 & 56.18 & 7.98 & 39.00 & 73.00 \\
\hline RMPT & 62 & 53.16 & 7.82 & 37.00 & 70.00 \\
\hline Delayed posttest & 62 & 47.15 & 7.07 & 35.00 & 66.00 \\
\hline
\end{tabular}

key: RMAT - Researcher made achievement test

RMPT - Researcher made performance test

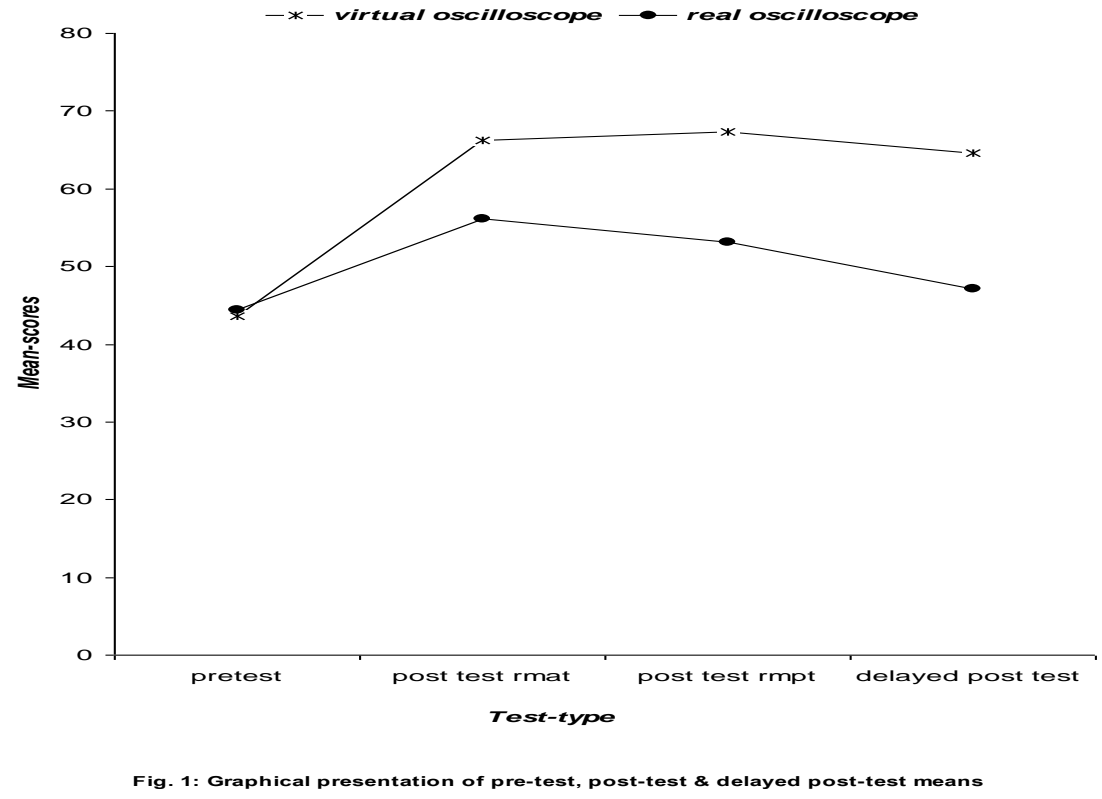

\subsection{Findings}

(i) The Virtual Oscilloscope was successfully tested with no problem. It could display various wave forms, measure voltages, time, and frequency and detect signals.

(ii) 62 RTE students attempted the RMPT, in the VO group, they had $67.32 \%$ mean score, 62 RTE students also attempted the RMPT, in the RO group, and they had $53.16 \%$ mean score. It was observed that, those in group VO had higher percentages.

(iii) RTE students in VO group were 62 that attempted the RMRT; they had a mean score of $64.66 \%$. Also, 62 RTE students in group RO attempted the RMRT and they had a mean of $47.15 \%$. This show, students that were taught using VO, retains better what they have learnt.

\subsection{Discussion of findings}

Data collected to answer research question one showed that, virtual oscilloscope (VO) was successfully tested with no problem. Various waveforms were observed from its output as they were monitored by the researcher. Similarly, with the VO, the researcher was able to calculate; voltage, time and frequency using the formula $\mathrm{F}=1 / \mathrm{T}$. The results also, show that, they could be used to detect signals/troubleshooting. The VO was able to indicate amplification of signals, the amplified signals also show replica of the input signal.

The results show that the VO has answered question one, which was to be able to display various waveforms, measure voltages and detect signals. This result is similar to that of [11] who designed and constructed personal computer oscilloscope (PCO) using computer software. When the PCO was interfaced to 
ADC hardware via the parallel port, it was found that, the PCO can be used in testing AC signal voltage, frequency and waveform of $2 \mathrm{HZ}$ to $50 \mathrm{KHZ}$ range.

The results in Table 1, posttest and delayed posttest means were 66.29 and 64.66 respectively. Similarly, the posttest and delayed posttest for group 2 were 56.18 and 47.15 respectively. In both groups learning occurred, but students in group 1(virtual oscilloscope) performed better. Also, the result further indicates, those in group 1, could retain what they learned over a period of time better than those in group 2. This shows the superiority of the VO over the RO. [12] and [13] confirmed this superiority, when they said, VO helps students to understand better the techniques and basic concepts used in laboratory work.

\section{Conclusion}

This paper examined the effectiveness of a virtual oscilloscope (VO) compared to real oscilloscope (RO), when used to teach two different groups of Radio, Television and Electronics work (RTE) students at the technical college level. The purpose was to determine if VO would be effective to teach RTE students at the technical colleges. The second purpose was to determine whether the VO would help the RTE students to retain what they have learnt longer.

Generally, male performs better in the Ge (VO) group than the female; the probable reason was that males are more literate in computer than their female colleagues. Female students should be encouraged, both at home and in school to be computer literate.

Due to its numerous advantages, which include large screen using projector for demonstration, easier to operate, portability, among others. All hands must be on deck, to see that the Virtual Oscilloscope is purchased by all concerned and used to complement the Real Oscilloscope for teaching not only RTE, but all related areas.

Workshop should be organized at all levels of education to introduce the use and the importance of Virtual Oscilloscope to practicing teachers. Such workshop should emphasize the various attributes of the Virtual Oscilloscope, which can be exploited for educational advantage.

\section{References}

[1] Federal Republic of Nigeria, National Policy on Education, $\left(2^{\text {nd }}\right.$ edition, Yaba, Lagos, 1985

[2] National Business and Technical Education Board Syllabus, Engineering trades (based on modular curriculum) Benin, NABTEB, 2003

[3] National Board for Technical Education (NBTE), Annual Examination Report. (Kaduna, NBTE, 2006, 2007\&2008)).

[4] H. A .Olumese, Vocational and Technical education in Nigeria. Issues, problems and prospects, Nigeria Journal of Curriculum studies 11(I) 2004, $73-77$.

[5] A. E.. Jega, An Investigation of the Relation between Academic Achievement of Students in Physics and Electrical Technology Programme, Journal of Technical Teacher Education, 4(6), 2004, $24-27$.

[6] L. Ohakwe, Problems and Prospects in the teaching and learning of Science. Nigerian Journal of Research in Education 1(1), 2004, $158-161$.

[7] J.D. Medugu, The effectiveness of a digital oscilloscope for the teaching of some Radio, Television and electronics work concepts at the technical college level, doctoral diss. Vocational and Technology Education programme, A.T.B.U., Bauchi, . 2011.

[8] J. L. Adeyanju, Production of cheap Instructional Materials for the 6-3-3-4 System of education with emphasis on the first six years. Trends and Research in Educational Technology, 2000, 45-53.

[9] E. N. Ezeanya., The status of instructional materials in schools, Nigeria Journal of curriculum studies, special, 2002, 67-73

[10] N. Bill, Computer as an Instructional aids. Journal of Educational Computing Research.5 (11), 2003, $431-444$.

[11] K. M. Abubakar, Design and Construction of Personal Computer Undergraduate Project. University of Maiduguri, 2004.

[12] O. T Balogun, Th.e Use of Computer Simulations as a Teaching Aid. Journal of Information Science 13 (4), 1996, 97-104.

[13] M, Vero, C. Garcia, and, G. Pedros, Computer in Physics International Journal of Science Education. 17(8), 2006, 157-171 